\title{
Training and maintaining autonomy-supportive supervisory style in low-skilled occupations.
}

\begin{abstract}
According to self-determination theory, employees' well-being is related to the autonomy-supportive style of a supervisor. However, the effect of supervision style on wellbeing remains under-studied in low-skilled occupations. This study employed a mixedmethod, multi-level approach to examine the impact of autonomy-supportive training (AST) on supervisors and employees and to identify factors contributing to the maintenance of supervisors' autonomy-support (SAS). The quantitative phase evaluated the effect of AST on supervisory style and employees’ well-being, with a sample of 44 supervisors and 240 employees in New Zealand. The qualitative phase used focus groups and interview with 15 supervisors to explore factors that could influence the maintenance of SAS. Overall, supervisors can be trained to adopt an autonomy-supportive style, but these skills can also be diluted by organisational factors such as pressures and managerial behaviour. This study contributes to autonomy-supportive style research in order to account for factors affecting the maintenance of SAS in low-skilled occupations.
\end{abstract}

Keywords: Training and development, leadership development, mixed methods, organisational climate, wellbeing and psychosocial risk factors.

\section{INTRODUCTION}

Employees in traditionally low-skilled industries such as manufacturing and some service sectors, contribute substantially to the economy and represent a significant proportion of the workforce. In New Zealand, the manufacturing industry employs up to $11 \%$ of the workforce and is responsible for $12 \%$ of the economy while service industries such as accommodation, restaurants and retail contribute another 9\% (Ministry of Business Innovation \& Employment, 2018). In the United States, the manufacturing industry hired 
54,000 more employees in 2018 compared to 2017, and the accommodation and food services industry hired 66,000 more employees in the same time period (U.S. Department of Labor, 2018). Despite their contribution to the economy and employment, the well-being of those in low-skilled occupations has often been neglected (Busch, Staar, Åborg, Roscher, \& Ducki, 2010).

Studies have shown that a well-designed job (e.g., high job autonomy, skill and task variety) and supervisors’ autonomy support (SAS) contribute to employees’ well-being (Güntert, 2015). While high job autonomy is consistently low among employees in lowskilled occupations (Wheatley, 2017), SAS, which enhances another facet of autonomypsychological autonomy (Baard, Deci, \& Ryan, 2004; Ilardi, Leone, Kasser, \& Ryan, 1993) may be a viable alternative to enhancing well-being in these jobs.

Psychological autonomy, a basic need as proposed by self-determination theory (SDT), is the need for an individual to make a rational choice and to act volitionally while being mindful of self and others' needs and demands (Chirkov, 2011). It is not independent of others, but employees make volitional decisions within the demands and needs of self and others. Autonomy along with competence and relatedness are basic needs, which when satisfied, lead to well-being (Deci et al., 2001). Supervisors are imperative in facilitating this path to well-being, as employees report to them.

Supervisors' support in low-skilled occupations tends to be a major predictor of employees’ well-being (Ariza-Montes, Arjona-Fuentes, Han, \& Law, 2018; Winkler, Busch, Clasen, \& Vowinkel, 2015). Nevertheless, SAS is distinct from supervisors' support, as SAS specifically enhances employees’ sense of autonomy through autonomy-supportive behaviours, therefore giving a more precise indicator of the type of supervision which contributes to the well-being of employees in low-skilled occupations. 
Winkler et al. (2015) called for future studies to train supervisors in low-skilled occupations on being supportive to improve employees’ well-being. Relatedly, autonomysupportive training studies have shown the positive effect of the training on supervisors and employees’ well-being (Deci, Connell, \& Ryan, 1989; Hardré \& Reeve, 2009). However, despite this success in higher-skilled occupations, training has yet to be conducted and the effect studied extensively in low-skilled occupations. By employing a mixed-method approach, this study aims to (1) quantitatively evaluate the outcome of autonomy-supportive training designed for supervisors in low-skilled occupations, and (2) qualitatively explore the factors that could influence the maintenance of supervisors’ supervisory style.

\section{Supervisors' autonomy support (SAS)}

SAS is a supervisory style which satisfies employees’ autonomy, competence (sense of effectiveness in engaging with work activities), and relatedness needs (connectedness between oneself and colleagues at work), leading to autonomous motivation and to wellbeing (Güntert, 2015; Oostlander, Güntert, \& Wehner, 2014; Slemp, Kern, Patrick, \& Ryan, 2018). Its opposite is the controlling style, where supervisors pressure the employees to behave in the supervisors' preferred way, leading to a lack of felt autonomy (Deci \& Ryan, 1985). While SAS satisfies needs, a controlling supervisory style tends to frustrate needs (Bartholomew, Ntoumanis, Ryan, Bosch, \& Thøgersen-Ntoumani, 2011).

Studies of SAS have identified four autonomy-supportive behaviours: (1) providing meaningful reasoning to help employees understand the task's value; (2) acknowledging employees' negative feeling when making an unappealing or difficult request and listening to employee's suggestions; (3) using informational language to communicate work requirements or feedback; and (4) nurturing inner motivational resources by allowing employees to outline their work processes, giving time for interaction with colleagues, applying adequate challenge to generate interest, and considering employees' personal and 
professional development (Deci et al., 1989; Deci, Eghrari, Patrick, \& Leone, 1994; Hardré \& Reeve, 2009).

The challenge with SAS in low-skilled occupations is that it be perceived as being permissive or not providing direction (Reeve, 2009), hence leading to the idea whereby detailing of work processes and guidelines should be avoided to be autonomy-supportive. Detailing work processes and guidelines are characteristics of low-skilled occupations due to the heavy influence of Taylorism (Taylor, 1911). However, according to Jang, Reeve, and Deci (2010), being autonomy-supportive is different from being permissive. They found that in a classroom, autonomy support correlated positively with communicating expectations, offering guidance, and constructive feedback. The key to autonomy-supportive supervision is in conveying work processes and guidelines by listening to and accepting employees' points of view, discussing corrective action and encouraging initiatives. Essentially, SAS is an applicable supervision style even in a routine and low job autonomy environment.

\section{Autonomy-supportive training (AST)}

Supervisors develop their supervisory style partly as a result of their traits and factors within their psychosocial environment (Olesen, 2011). As supervisory style can be influenced by factors external to their traits, it is possible to train supervisors to adopt an autonomysupportive supervisory style. AST has been conducted with various target participants, such as teachers (Cheon, Moon, \& Reeve, 2012; Cheon \& Reeve, 2015; Reeve \& Cheon, 2014), coaches (Langan, Blake, Toner, \& Lonsdale, 2015), healthcare professionals (Lonsdale et al., 2017; Murray et al., 2015) and parents (Joussemet, Mageau, \& Koestner, 2014).

AST with teachers has shown that the training increased students' perception of teachers’ autonomy support, enhanced need satisfaction and academic achievement (Cheon et al., 2012), decreased need frustration and burnout for students, and enhanced teachers' well-being when they practised autonomy-supportive teaching styles (Cheon, Reeve, Yu, \& 
Jang, 2014). AST with managers, in particular, was found to increase work engagement and satisfaction among employees when supervisors practise a more autonomy-supportive style (Deci et al., 1989; Hardré \& Reeve, 2009). Therefore, supervisors trained in autonomysupportive behaviours may be viewed by employees as more supportive, leading to enhanced need satisfaction, prevention of need frustration and other positive organisational outcomes in employees.

Studies have shown that AST can be used to equip supervisors with autonomysupportive skills, but the maintenance of skills learned after training is vital for maximising the benefit of such training. The next section reviews the conditions that might affect the maintenance of SAS.

\section{Maintaining SAS}

While training is useful to inform and encourage SAS, the maintenance of SAS requires more than a training session. Grossman and Salas (2011) mentioned that even the best of all training designs would have no effect if the work environment does not support the use of skills learned in the training session. According to Stenling and Tafvelin (2016), an organisational autonomy-supportive climate predicted the application and integration of new autonomy-supportive knowledge and skills one year after they were learned in training. An organisational autonomy-supportive climate includes perceived support from the immediate manager of supervisors (Chiaburu, Van Dam, \& Hutchins, 2010). The term "manager” in this article, refers to someone whom the supervisors report to. Other studies suggest wider organisational factors such as pressure could potentially affect supervisory style. For example, supervisors who experience high pressure tend to become less autonomy supportive (Pelletier, Séguin-Lévesque, \& Legault, 2002) and teachers who experience pressure from multiple sources including from their superior also tend to adopt a more controlling style (Deci, Speigel, \& Ryan, 1982; Reeve, 2009). 
Similarly, organisational and personal factors can affect employees' perception of SAS and in turn undermine the effect of training. Studies have suggested organisational factors, such as pay, benefits, job security, the climate of tension and interactions within the organisation (Deci et al., 1989; Hitt, Beamish, Jackson, \& Mathieu, 2007), have influence over employees' perception of SAS. Furthermore, employees who exhibit autonomous motivation may view their supervisors as more autonomy supportive, while employees who exhibit controlled motivation may view their supervisors as less autonomy supportive (Beenen, Pichler, \& Levy, 2017).

To summarise, supervisors and employees can each provide different perspectives on various factors influencing the training effect. However, this study focuses on exploring factors affecting the maintenance of SAS from the supervisors' perspective for three reasons. Firstly, Ryan and Deci (2017) suggest that interpersonal climate demonstrated by supervisors can influence employees’ perception of support or control. Moreover, students perceived their teachers as more autonomy-supportive and experienced greater need satisfaction when teachers use more autonomy-supportive behaviours (Cheon et al., 2012). Clearly, SAS is part of the climate that positively impacts employees' perception of SAS and need satisfaction. Therefore, by maintaining SAS, employees can experience the positive effect of SAS on their well-being.

Secondly, many of the factors that could affect the maintenance of SAS are within the control of the organisation, either in the form of policy or culture, as discussed above.

Studying the maintenance of SAS provides organisations with "actionable" areas (Colquitt \& George, 2011) to support the ongoing practice of SAS, which in turn advances the well-being of employees in low-skilled occupations.

Finally, Baldwin, Ford, and Blume (2017) suggested researchers should understand trainees' contexts (e.g., organisational environment) to optimise the application of skills after 
training. Therefore, understanding organisational factors affecting SAS can guide organisations and researchers to design training that may result in the ongoing application of SAS in low-skilled occupations. Thus, this study focuses on exploring factors that could affect the maintenance of SAS.

\section{Research questions}

In summary, despite its potential to improve well-being for low-skilled workers, the effectiveness of AST for supervisors remains untested. In addition, how organisational factors affect the maintenance of SAS is underexplored in low-skilled occupations. To address these gaps, this study aimed to answer three questions: (1) Does AST increase SAS among supervisors? (2) Does AST increase employees' perception of SAS and need satisfaction, and reduce need frustration? and (3) How do organisational factors influence the maintenance of SAS?

In line with these research questions, for the quantitative phase, we hypothesised that (1) AST increases SAS and (2) AST increases employees' perceived SAS and need satisfaction, and decreases employees' need frustration.

\section{METHOD}

This study used a mixed-method approach with expansion as the intent (Greene, Caracelli, \& Graham, 1989). This approach strives to understand a range of different components relevant to the topic by employing different methods to study them. The quantitative phase aims to model change in supervisory style, and employees' perception of SAS, need satisfaction and frustration across time, by implementing and evaluating AST using a quasi-experimental design with intervention and waitlist control group. The qualitative phase aims to explain the factors that might influence the maintenance of SAS using focus groups and interview methods.

Quantitative phase 


\section{Participants}

A total of 44 supervisors and 240 employees from three factories (packaging and food industries) and a 4-star international hotel chain in New Zealand participated in the study. All these organisations were selected as they shared the similarities of following routine work processes and hierarchical management style. Sixteen of the supervisors were assigned to the intervention group, while 28 were in the waitlist control group. Among the supervisors, $75 \%$ were male, $22.7 \%$ were female and $2.3 \%$ did not specify their gender, while $59.1 \%$ were supervisors of factory operators and $40.9 \%$ were supervisors of various service occupations. On average, the supervisors had worked in their organisations for 10 years (SD = 8.3) and been in a supervisory role for 5.7 years $(\mathrm{SD}=6.4)$. It is important to note here that supervisors' direct reports varied due to shift patterns. Because of this, supervisors had between 1 and 42 employees completing surveys about them, with an average of 14 responses per supervisor.

Of the 240 employees, $43.2 \%$ of the employees had supervisors who were assigned to the intervention group, while $56.8 \%$ of the employees had supervisors who were assigned to the control group. The mean age of the employee participants was 37.7 (SD =13.3). Most of the employee participants were male (64.6\%), 28.8\% were female, and 6.7\% did not specify their gender. While $72.9 \%$ of the employee participants worked as factory operators across various industries, $27.1 \%$ of employee participants worked in various service occupations (e.g., housekeeping and frontline service).

\section{Procedure}

The quantitative phase adopted a quasi-experimental approach, with an intervention and waitlist control group and survey measurements at three times. Supervisors of each organisation were assigned to an intervention or waitlist control group in consultation with the human resource personnel or factory manager. This method of assignment was chosen to 
accommodate the supervisors' work schedule and rotation of workstation management among supervisors. Supervisors were invited to participate in AST and to complete surveys assessing their supervisory style. At the same time, meetings were organised with their direct reports to invite them to participate in the study by filling in surveys. Surveys with the supervisor's code were distributed to the respective employee. Confidentiality was maintained through anonymous survey forms, with two unique identifier questions used to track the survey forms across time (e.g., date and month of birth).

All supervisors and employees were given the surveys one week prior to the training with the supervisors in the intervention group (Time 1 surveys) to allow supervisors time for mental preparation leading to the training and the trainer to contextualise examples used during the training. The surveys were re-administered to all supervisors and employees 2 weeks post-training (Time 2 surveys) and again at 8 weeks post-training (Time 3 surveys). Finally, the research process ended with training for the waitlist control group supervisors. Studies involving autonomy-supportive training have evaluated the effect ranging from 2 weeks, 2 months to a year (Aelterman, Vansteenkiste, Van Keer, \& Haerens, 2016; Lewis et al., 2016). However, evaluation beyond 3 months is not recommended for studies involving employees in low-skilled occupations, due to high attrition risk (Busch, Koch, Clasen, Winkler, \& Vowinkel, 2017). Figure 1 illustrates the timeline and the research procedure [insert Figure 1].

\section{Autonomy-supportive Training (AST)}

The training material was developed following the recommendations from Su and Reeve (2011) and the adult learning principles by Knowles, Holton, and Swanson (2012). Prior to the training, a pilot AST was conducted with 11 supervisors from two organisations. Feedback on the practicality, ease of understanding and delivery method of the AST was collected. The final training material was modified with reference to the recommendations of 
the pilot participants. An example of the modification is changing the word from "block" to "stop” for clarity in the original question, “what might block you from practising an autonomy-supportive approach?” All training was conducted by the first author.

The AST consisted of a 3-hour training (Part 1) and a 1-hour follow-up (Part 2) 2 weeks after the training. Part 1 was divided into two sessions. Supervisors were given a booklet of the training content at the beginning of the session as supplementary material. In part 1 , each of the four autonomy-supportive behaviours was presented to the supervisors using examples and discussion. The first session was about 1.5 hours. The second session of part 1 consisted of a work scenario discussion and goal setting, where supervisors were encouraged to share their goals during the follow-up session. Part 2 of the AST consisted of goal reviews and setting of longer-term goals (Authors, 2019).

\section{Measures}

Supervisory style

The supervisory style frequently practised by the supervisors was measured using the Problems at Work scale (PAW) by Deci et al. (1989), adapted from the Problems in Schools questionnaire (Deci, Schwartz, Sheinman, \& Ryan, 1981). The scale consisted of eight work scenarios with four responses following each scenario. The scenarios comprised of issues supervisors might encounter with employees, such as One of the customers has let you know that he is not very satisfied with the attitude of his service representative. Following the scenario, supervisors rate the appropriateness of the responses on items such as Tell him (employee) to see to it that the customer is more satisfied and let him know you will be checking up on him on a 7-point scale ranging from 7 Highly appropriate to 1 Highly inappropriate. The four responses within the scenario reflected four management styles: highly controlling (HC), moderately controlling (MC), moderately autonomy-supportive (MA), and highly autonomy-supportive (HA). 
Supervisors’ Autonomy Support

Employees’ perception of SAS was assessed using the Work Climate Questionnaire (WCQ) adapted by Baard et al. (2004) from Williams and Deci (1996) $(\alpha=.96)$ and Williams, Grow, Freedman, Ryan, and Deci (1996) $(\alpha=.92)$. The WCQ is a 15 -item questionnaire, with items such as I feel understood by my manager, and participants rated their perception of SAS from a 7-point response scale ranging from 7 Strongly agree to 1 Strongly disagree.

Need satisfaction and frustration

The satisfaction and frustration of employees’ basic psychological needs were measured using the 24-item Basic Psychological Need Satisfaction and Frustration at Work scale (BPNSF-W). The scale was adapted by Schultz, Ryan, Niemiec, Legate, and Williams (2015) to the work domain from the general scale developed by Chen et al. (2015). The Cronbach's alpha for the need satisfaction scale was 0.90 , and 0.88 for need frustration. The need satisfaction scale uses items such as At work, I feel capable at what I do and the need frustration scale uses items such as I feel insecure about my abilities on my job, and employees rated the items from 1 totally disagree to 7 totally agree.

\section{RESULTS}

\section{Supervisory style}

The four supervisory styles can be averaged into a single composite score, which demonstrates the overall supervisory style, or evaluated as four separate styles. We chose to evaluate the supervisory styles separately to test how the training affected each of the supervisor's supervisory style. Mean differences across time for the four supervisory stylesHA, MA, MC and HC-were analysed separately for supervisors in the intervention and control group using repeated-measures ANOVA. The results show Mauchly's sphericity test was not violated. There is a difference in MA style for supervisors in the intervention group 
only across the three time points $\left(F(2,14)=8.51, p<.05, \omega^{2}=.55\right)$. Supervisors in the intervention group showed increased in MA style at Time 2 as compared to Time 1, but not from Time 2 to Time 3 and there was no significant decrease in controlling style. Figure 2 illustrates the mean differences of supervisory styles (HA, MA, MC and HC) across time between the intervention and control group.

[insert Figure 2]

Employees' perception of SAS, need satisfaction and need frustration

Changes in SAS, need satisfaction and need frustration as felt by employees whose supervisors attended the training, was analysed using growth curve modelling. This analysis was chosen as it does not assume independence and is able to handle incomplete datasets, which is crucial, as participants did dropout from the study (Twisk, 2006). Moreover, it estimates variable change between individuals (Level 2) and change within a person (Level 1).

We begin by modelling growth with a linear trend as the base model using Maximum Likelihood estimation for SAS, need satisfaction and need frustration. Time was our predictor and SAS, need satisfaction and need frustration was the dependent variable with autoregressive covariance structure for random effect. Contrary to expectations, the result showed no significant increase in SAS, employee need satisfaction or decrease in need frustration. Table 1 shows the results of the linear trend analysis for the intervention group. [insert Table 1]

\section{DISCUSSION}

Training supervisors in autonomy-supportive behaviours resulted in an increase in autonomy-supportive supervisory style in the first post-intervention survey. The change in supervisory style once again confirms the malleability of supervisory style as demonstrated in studies by Deci et al. (1989) and Hardré and Reeve (2009). However, the effect did not 
persist into Time 3. This finding is similar to the study by Reeve, Jang, Carrell, Jeon, and Barch (2004) with teachers, which found no difference in autonomy-supportive behaviour between Time 2 and Time 3 assessment for teachers who did not receive further autonomysupportive instruction after Time 2 assessment. The findings suggest although supervisors can be trained to be more autonomy-supportive, it is just the first step to changing supervisory style. The maintenance of SAS will need to take into consideration other organisational factors, which will be explored in the qualitative phase.

AST is expected to not only affect supervisory style but also be felt by employees. However, employees did not report an increase in perceived SAS and need satisfaction or decrease in need frustration after supervisors participated in AST. Our findings were inconsistent with the findings of other studies (Hardré \& Reeve, 2009; Reeve \& Cheon, 2014). However, organisational factors and SAS are known to affect employees’ perception of SAS and need satisfaction (in the section "Maintaining SAS"). As there was no change in SAS beyond the first post-intervention survey, we suggest this also influenced employees’ perception of SAS and need satisfaction. The findings also emphasise the value of maintaining SAS for employees to experience such an effect.

Apart from broadening the understanding of SAS as the primary intent of using a mixed-method, the approach is now also intended to provide explanation on related issues that occurred in the research process (Creswell \& Plano Clark, 2017). In this case, the issue is that the intervention effect was not felt by employees. Based on the review earlier (in the section “Maintaining SAS”), we hypothesised that supervisors' environment influenced their supervisory style and employees’ perception of SAS. Hence, we conducted a focus group with supervisors to understand their work environment while issues related to the outcome of AST in the quantitative findings were woven into the discussion.

\section{METHOD}




\section{Qualitative phase}

\section{Procedure}

This phase used focus group and interview methods to uncover factors that could influence the maintenance of SAS and the relationship between supervisors and employees. An email was sent to the human resource personnel or factory manager to invite supervisors of the four organisations who attended AST to participate in the focus group. Two factories and a hotel responded to the invitation and a meeting with the supervisors was held in each organisation. The first author explained the focus group purpose and invited the supervisors to participate in it. An interview option was also available for supervisors who were unable to attend the focus group. Consent for audio recording was obtained from participants. To protect the confidentiality of participants, anonymity was assured, and ground rules were established to keep the information discussed within the focus group only. Participants were free to withdraw from the focus group at any time if they felt uncomfortable discussing the topics.

A focus group approach was chosen as it allows for interaction between supervisors in the organisation. Such group interaction can provide valuable information about similarities and differences of view from various departments and as members of an organisation which, an interview alone could not (Morgan, 1997). A focus group also provides the opportunity to observe difficulties that may arise in communicating information considered as sensitive (Wellings, Branigan, \& Mitchell, 2000), such as information about their manager or employees.

Following the procedure outlined by Morgan (1997), the prompt questions were general instead of narrow to avoid limiting the data and to encourage discussion. Furthermore, focus groups were conducted using a funnel strategy, starting with general prompt questions followed by specific question (e.g., how pressure affected their relationship 
with employees). As proposed by Holstein and Gubrium (1995) participants were also given an information sheet at the beginning of the focus group, describing the training and survey they participated earlier to provide context to the discussion. In summary, we drew on various methods in conducting focus group to achieve the research objective.

Based on the review earlier, factors that might affect the maintenance of SAS included the managerial relationship with supervisors and various types of pressure. These factors, in turn, could affect employees' perception of SAS. Therefore, the focus groups aimed to explore (1) supervisors' relationships with their managers and employees, and (2) the source and effect of pressure on their role as supervisors. A series of prompt questions were directed to the participants during focus groups. An example of the prompt question was: Tell me about the relationship you have with your own managers/bosses?

\section{Sample}

A total of three focus groups (ranging from three to seven participants in a group) were conducted with 14 participants. An interview using the same prompt questions was conducted with one supervisor who was unable to attend the focus group during the day. Overall, the participants consisted of 3 females and 12 males. Focus group 1 consisted of three supervisors from a factory, group 2 consisted of four supervisors from the hotel, and group 3 consisted of seven participants from the factory, though four of the participants left before the focus group ended.

\section{Analysis}

Inductive thematic analysis was used to analyse the focus groups and interview data. The phases of thematic analysis suggested by Braun and Clarke (2006) were used in this study. In phase 1 , the first author transcribed the audio recordings and became familiar with the data through reading and re-reading the transcriptions. Moving to phase 2, initial codes were generated by going through the entire transcribed dataset. In inductive thematic 
analysis, code generation is driven by data, hence, the entire dataset was coded without looking for theory-specific information. Codes were generated from each transcription separately and combined into a single list of codes before searching for several possible themes (phase 3). An initial mind map was used to represent the possible themes, and themes were reviewed and refined for internal consistency and heterogeneity (phase 4). Finally, in phase 5, themes were defined and named with agreement from all the authors.

\section{RESULTS AND DISCUSSION}

Figure 3 presents the three main themes identified along with the sub-themes and codes. The themes will be described with narratives from the participants.

[insert Figure 3]

\section{Relationship with managers}

\section{Perception of manager}

Supervisors’ perception of their managers tends to vary from one manager to another, but there was consistency among supervisors when they discussed the same manager. For example, supervisors who were from the same organisation perceived their manager as supportive and providing job autonomy to them.

I don't have any issue with Manager L, always been supportive of me so... I get to do what I want to do without anyone micromanaging me, which is always good and he doesn't expect to micromanage people otherwise as he says, "why would I employ you if I have to micromanage you?” (T1).

On the other hand, supervisors from the other two organisations felt a lack of support from their manager. Supervisors felt guidance or feedback were not provided for them to successfully accomplish their tasks or there was a lack of understanding from their managers when targets were not achieved. 
Normally, when you have your views and um what not... you... you know... put out some things you wanna get done and nothing really happens (C13).

Manager M comes down on me, "why are they taking this long in the room?” Well, hang on... ah... ok... We've only got 1 vacuum on the floor and three teams (N 12).

Overall, the lack of managerial support reported by a majority of the supervisors was prominent in the discussion, hence leading to the following sub-theme.

\section{Controlling managerial style}

In two of the organisations, participants seemed hesitant discussing issues such as being held responsible over unmet performance standards, not being consulted or informed about decisions made, and inflexible working conditions set by the management. They used words like "they," "above” or making hand gestures pointing to offices of the management staff in conversing about their manager or a manager from the upper management. Such observation carried the sentiment that discussing negatively about their manager or upper management staff might lead to negative repercussions. This reflects a controlling managerial style perceived by supervisors (Slemp et al., 2018).

When the machine's down for the day, you get behind. And then you get us leaders get looked at. Eyes in the back. Cause that's our job is to make sure it gets done (C18). When you get the pressure from like I said above and I have to relay that on the team and say, "look, you're taking too long, and then what's going on blah blah blah." “Oh, you know ra ra ra," and then as I'm walking away, I can just hear "that bitch” (N12).

According to Deci et al. (1982), teachers who were told in a controlling manner that they are responsible for students’ performance were in turn, controlling of the students. Therefore, we suggest supervisors operating under a controlling management style tend to also use a more controlling approach and reprimanding language (e.g., you're taking too 
long, what's going on?) and be less motivated to proactively consider employees’ development.

Furthermore, other organisational studies have shown the detrimental effect of managerial negative behaviours on supervisors and employees (Mawritz, Mayer, Hoobler, Wayne, \& Marinova, 2012). In line with our findings, a controlling managerial style not only resulted in supervisors' controlling behaviour but also resulted in employees' unmotivated and unproductive behaviours. Beyond behaviours, employees' well-being was also substantially affected by the controlling style. This demonstrates how higher-level relationships (managers) can impact employees.

And you're working and trying really hard, and somebody comes out and just sticks the knife at you... (C4). Yeah, how do you feel?... I'll go home and not come back (C13). Yeah, I mean it just shatters your whole, you know, productivity. You start going over the hill. Nobody else gives a s*** (C4). And that's what we're finding is there's a lot of people that are don't care anymore... yeah... and that's reflected in productivity. So, it’s just trying to... (C1).

If she's not in a good mood, then the whole department is not in a good mood. It's taken it out on everybody (N12).

In summary, autonomy-supportive studies have commonly been interested in proximal autonomy support, especially by direct authority figures such as managers (Baard et al., 2004; Hardré \& Reeve, 2009), teachers (Cheon et al., 2012) and coaches (Langan et al., 2015). Recently, a meta-analysis by Slemp et al. (2018) found that leaders' autonomy support, regardless of the proximity (direct leader or senior leaders), facilitated employees' need satisfaction. However, the effect of controlling style from managers to supervisors and employees has not been investigated. While leaders' autonomy support regardless of proximity can benefit employees, in our study, the lack of autonomy support 
from the managers (distal leaders) seems to leave the supervisors (proximal leaders) with insufficient support to function in their role, let alone be autonomy supportive. This presents a challenge in the maintenance of SAS and the betterment of employees' wellbeing.

Working environment

Lack of resources

Supervisors across all three organisations noted that they had insufficient resources, such as staffing, facilities and training, to successfully accomplish their tasks. This represented a wider organisational issue, which goes beyond the lack of support provided by managers. The staffing issues were related to employee retention, finding the right fit for the job and budget constraints. Their account contrasts with the popular belief that employees in low-skilled occupations are easily replaced.

Ah well, they have all the people at the head office up there learning all about it and knowing all the system. People down here, like Supervisor P, W and I had to use it every day, we haven't been shown a thing about it (T2).

Be good to have another staff on desk so I'll be able to do all these... do all these tasks and get more sorted... with 5 staff, it's just a bit difficult. But sometimes we need it because we just running around sorting out the cars, sorting out the guests and everything just gets backed up (N1).

Pressure from within the organisation

Supervisors from all three organisations felt the pressure from within the organisation, mainly from other departments. As their jobs operate in a chain, delay in one department tends to snowball to another, sometimes resulting in strained relationships among departments or within the department among supervisors and employees. Although a few supervisors described the pressure as constant, most felt the pressure from within the 
organisation can result in them feeling stressed and having to extend their role, thus working longer hours or having to "be on the floor" to accomplish the task.

And I say, "how am I gonna make those products in the shift?” "Oh, it was asked to be cut this morning so you could start off on it tonight to make the products." "Well, obviously it hasn't been cut." So now we're gonna go and change every machine (T4).

Someone like rung me and ask me for rooms, and I go to these girls and I go, "you just stop what you're doing please, and move on to this room. Reception would like this room.” And then, they're like, "oh, reception needs to come down here and see what it blah blah blah," they don't see why, and so, I sorta put them in their place and go, "actually no, it's not reception, the guest is here now" (N12).

\section{Pressure from outside the organisation}

A number of supervisors also felt pressured by sources outside the organisation, such as customers, resulting in a feeling of frustration that could also result in strain among and within departments. This direct pressure from customers was most related to occupations in the service industry. Such pressure can also be less predictable, as individual customers tend to vary and customer turnover is high.

[Customers are] like... no, I want it now. It's like, it's hard... like... yeah they don't think that the staff, they actually need a break... like... I've been away for dinner and the receptionist says, "ah, the duty manager is just at dinner" (pause) and the guest was like, "why is he at dinner? He should be helping me" (N1).

Reeve (2009) categorised the sources of pressure experienced by teachers from within or outside the school as "pressure from above” (p.164). We have chosen to distinguish between two sources of pressure, as not all supervisors experience direct pressure from outside the organisation. Distinguishing the sources of pressure demonstrated how pressure 
was "transferred" to supervisors, which provides an understanding of the process leading to the supervisory style. Although the paths in which pressure was transferred to supervisors differ, both can result in supervisors feeling stressed and frustrated, further leading to experiencing strained relationships with employees or other departments. Similar to the proposition by Reeve (2009), when teachers experience pressure from administrators or state standards, they tend to absorb and pass it on to the students in the form of a controlling teaching style.

According to Hockey (1997), one of the ways employees handle pressure beyond their comfort level is to exert effortful strategies to meet demands while adopting a strategy that requires less effort in other tasks. The pressures and lack of resources as experienced by supervisors is characterised as pressure beyond supervisors' comfort level. The pressure led them to spend their energy dealing with demands while adopting an approach requiring less effort when supervising employees. Rigby and Ryan (2018) mentioned that controlling approaches are effective and quick to command change, especially for short-term behaviour. With high demands, supervisors adopt a controlling approach, which would require less effort to handle staff-related issues. However, this is done at the expense of compromising longterm motivation and performance, as seen also by our results, whereby need satisfaction and frustration remains stagnant when employees’ perception of SAS remains unchanged.

\section{Supervisors' interaction with employees}

\section{Consistency in contact}

The majority of the participants reported having inconsistent contact with their employees, suggesting difficulty in their supervising role. About half of the respondents reported that their employees tend to have inter-departmental movements based on departmental needs and employees' skill sets, while other supervisors work with their team based on shifts. A few supervisors rotate their shifts to fill in on each other's days off. 
At the moment, there's 2 guys making (something) for assembly. If tomorrow

Supervisor P got a whole lot of work in, then those 2 guys will automatically start in Supervisor P's department again (T1).

Every week it changes... I mean it is the nature of the job in Department F, like it does rotate. You do have to just work around it (N1).

The inconsistency in contact between supervisors and employees can play a major role in the effect of AST not being clearly reflected in employees' well-being, as some employees might report to a supervisor who has attended AST while other supervisors have not. A similarly designed study on personal growth leadership intervention by Elo, Ervasti, Kuosma, and Mattila-Holappa (2014) was also unable to detect difference between the control and intervention group for perceived supervisors' behaviour and employees' wellbeing. One of the reasons cited for the weakened effect was the lack of contact between supervisors and the mainly blue-collar employees. Apart from frequency in communication, Vidyarthi, Erdogan, Anand, Liden, and Chaudhry (2014) found that employees made comparison between two leaders, and the comparison would affect employees' attitudes and behaviours. Having different supervisors might lead to comparison, thus affecting employees’ perception of SAS, particularly if both supervisors have a different supervisory style.

\section{Use of different supervisory styles}

Supervisors tend to experience tension with employees when there were noncompliant behaviours or unmet targets. They mainly used a confrontational approach or punishment for undesirable behaviour, thinking that it has worked for them in dealing with employees' issues in the past.

Yeah, like we all jump on them straight away as soon as they start missing days and everything like that, um... yeah, I think like Supervisor P and A, I do my best for the guys in here but I'm not here to hold their hands and wipe their bums for them. I'll 
help them as much as I can, I'll be their mate when I have to be. I'll be their boss when I have to be but I'm not gonna tell you how to run your life. That's your problem. You don't want to turn up for work, you don't get paid, I'll finally push you out the door (T2).

Like I always stood my position that I wouldn't change anything. For the last 30 years-I've been supervising for that long-at the end of the day, always open for different ideas but the basics of supervising people are still the same (T1).

On the other hand, a small number of supervisors used reasoning to negotiate employees' discontent and work demands.

I always tell the team if there's no linen, there's no room. That's why like I always talk to my team we must push the linen as fast as we can (N15).

That's what I will explain to the guys. It's not an every night thing. You gotta expect we do get behind on things cause you have got machine breakdowns and you have to catch up on other stuff first (T4).

Some of the supervisors seem to be demonstrating a more controlling approach by using punishment to correct perceived noncompliant behaviour, while a few maintained a more autonomy-supportive approach by using reasoning to communicate expectations to the employees. In line with Reeve's (2009) proposition, supervisory style can also be influenced by their belief about how effective the supervisory style is. Although supervisors' belief can influence their style, Stenling and Tafvelin (2016) point towards organisational autonomysupportive environment as the major factor of long-term autonomy-supportive practice. Therefore, to maintain SAS, the preeminent factor lies within the organisation, while individual belief is acknowledged as additional factor.

\section{GENERAL DISCUSSION}


The purpose of this study was to (1) evaluate the effect of AST for supervisors and employees in low-skilled occupations and (2) explore factors that could affect the maintenance of SAS. This study is novel, as AST has not been conducted with supervisors nor the effect evaluated with supervisors and employees in low-skilled occupations. Moreover, the factors that could influence the maintenance of SAS have also not been explored in organisational context, particularly in low-skilled occupations. Figure 4 presents the overall conceptual model resulting from this study. [insert Figure 4]

The quantitative results showed supervisors who attended AST demonstrated change in their supervisory style in the first post-intervention survey, but the employees showed no change in regards to perceived SAS, need satisfaction and frustration. The qualitative results showed that contextual factors such as managers’ behaviour, lack of resources, various sources of pressure, inconsistent contact and supervisors' beliefs can affect the maintenance of SAS. As Inceoglu, Thomas, Chu, Plans, and Gerbasi (2018) suggest, contextual factors can act as moderators of supervisor-employee interactions, and we suggest these contextual factors have weakened the effect of AST on employees’ perceived SAS.

Additionally, supervisors experience pressure from different sources, which we suggest resulted in a controlling approach and lack of SAS felt by employees. Kühnel, Sonnentag, and Bledow (2012) found employees cope better if resources provided correspond with demands. Therefore, we propose managerial autonomy support and adequate resources would help supervisors deal with the demands better, consequently maintaining SAS and the effect felt by employees. In line with Shanock and Eisenberger (2006) findings, future studies may consider testing the relationship and taking these factors into consideration as antecedents to supervisory style. 
As supervisors' support is seen as one of the representations of organisational support which leads to employees’ well-being (Rhoades \& Eisenberger, 2002), we recommend establishing plans for leadership development upon initially taking up supervisory roles, especially when a consistent reporting line is relatively difficult to plan for. That way, even though employees might report to different supervisors in different shifts or departments, they would still benefit from leadership development that all supervisors have learned during training.

Finally, leadership behaviours, especially the use of an autonomy-supportive style in lower-skilled occupations, warrant more attention, as it does seem to be lacking not just in the immediate supervisors but in higher levels of management as well. The controlling managerial style showed an impact that extends beyond affecting supervisor-employee relationship to employees’ well-being. As low-skilled occupations contribute to a substantial percentage of employment and the economy, it is crucial to focus on employees' well-being by establishing a supportive leadership style throughout the organisation.

\section{LIMITATIONS AND FUTURE RESEARCH}

The results of the study should be interpreted with awareness of the limitations. First of all, the factors that could limit SAS were explored using focus groups and interview method and may not be generalisable to the wider population. In focus groups, participants might have responded in agreement or been uninvolved when discussing their manager or employees, due to the sensitivity of the topics and confidentiality concerns. These limitations were addressed by assuring confidentiality and allowing participants to withdraw from the discussion at any time; and conducting the focus groups away from the offices of their manager or upper management. Additionally, using Zeller's (1993) guide to encourage diverse opinion around sensitive topics, the facilitator acknowledged participants' experience, probed for clarifications and avoided reacting to the comments with surprise or 
disapproval. While strategies are in place to address the limitations, future studies may consider conducting in-depth interviews with a few members from each organisation to validate findings or conduct experimental or longitudinal studies to establish the degree of influence the factors have in contributing to supervisory style and employees’ well-being.

Secondly, in relation to the setting of intervention and control group within the organisation, the inconsistent contact between supervisors and employees needs to be taken into account if researchers are to conduct intervention studies with employees in low-skilled occupations. Future research might consider comparing two similar organisations or between branches, rather than setting up intervention and control groups within each organisation. As post-intervention surveys were taken 1 week, 2 weeks and 2 months after the intervention, it was difficult to ascertain the fluctuation of well-being in terms of need satisfaction. According to Inceoglu et al. (2018), longitudinal studies could benefit from research design that is able to capture the fluctuation of well-being. Diary study design could potentially provide more robust information of the intervention effect.

Thirdly, the study is conducted in the context of low-skilled occupations in New Zealand. Winkler, Busch, Clasen, and Vowinkel $(2014,2015)$ suggest that potentially small sample size and/or scales appearing more complex to employees in low-skilled occupations may introduce validity issues to the scales used. Apart from the PAW, the structural validity and reliability of all the scales were satisfactory (Cronbach's alpha above .70). However, future studies are needed to ensure scale validity of the PAW with supervisors in low-skilled occupations. In addition, organisations attempting to apply the knowledge of training and maintaining SAS of this study might want to adapt the findings according to the relevant context. On the other hand, future research could study the similarities and differences of training and maintaining SAS in different work contexts, such as those in 
higher-skilled occupations, as Beenen et al. (2017) suggested the level of SAS required might differ according to the level of task identity in the job.

Finally, researchers should also consider exploring factors affecting employees’ perception of SAS qualitatively. In doing this, researchers should also be aware of the potential difficulty in getting a group of employees out of their processing or service line for further in-depth study. Therefore, a short interview method might be preferred instead of focus group or an in-depth interview.

\section{CONCLUSION AND PRACTICAL IMPLICATIONS}

This study has shown that AST conducted in a less autonomous and highly routine work environment can induce a minor change in supervisory style. The main findings in the autonomy-supportive supervisory style were highlighted. Firstly, training can be the first step to educating supervisors on an autonomy-supportive supervisory style. However, as discussed in the qualitative phase, the lack of managerial autonomy support can affect the maintenance of SAS. Thus, we suggest offering AST to various levels of management to support first-level supervisors in becoming more autonomy supportive. Moreover, the lack of essential resources and pressure were also found to affect supervisor-employee relationship. Therefore, providing essential resources such as equipment, training and staffing to accomplish tasks is necessary for supervisors to manage the pressure and redirect their focus to improve their interaction with employees. Finally, with the influence of top and middle leadership on SAS, an autonomy-supportive leadership development plan which includes top and middle-level management, and supervisors, is crucial for employees to gain the full benefit of SAS. 


\section{References}

Aelterman, N., Vansteenkiste, M., Van Keer, H., \& Haerens, L. (2016). Changing teachers' beliefs regarding autonomy support and structure: The role of experienced psychological need satisfaction in teacher training. Psychology of Sport and Exercise, 23, 64-72. doi:10.1016/j.psychsport.2015.10.007

Ariza-Montes, A., Arjona-Fuentes, J. M., Han, H., \& Law, R. (2018). Work environment and wellbeing of different occupational groups in hospitality: Job Demand-Control-Support model. International Journal of Hospitality Management, 73, 1-11. doi:10.1016/j.ijhm.2018.01.010

Baard, P. P., Deci, E. L., \& Ryan, R. M. (2004). Intrinsic need satisfaction: A motivational basis of performance and well-being in two work settings. Journal of Applied Social Psychology, 34(10), 2045-2068. doi:10.1111/j.1559-1816.2004.tb02690.x

Baldwin, T. T., Ford, J. K., \& Blume, B. D. (2017). The state of transfer of training research: Moving toward more consumer-centric inquiry. Human Resource Development Quarterly, 28(1), 17-28. doi:10.1002/hrdq.21278

Bartholomew, K. J., Ntoumanis, N., Ryan, R. M., Bosch, J. A., \& Thøgersen-Ntoumani, C. (2011). Self-determination theory and diminished functioning: The role of interpersonal control and psychological need thwarting. Personality and Social Psychology Bulletin, 37(11), 14591473. doi:10.1177/0146167211413125

Beenen, G., Pichler, S., \& Levy, P. E. (2017). Self-determined feedback seeking: The role of perceived supervisor autonomy support. Human Resource Management, 56(4), 555-569. doi:10.1002/hrm.21787

Braun, V., \& Clarke, V. (2006). Using thematic analysis in psychology. Qualitative Research in Psychology, 3(2), 77-101. doi:10.1191/1478088706qp063oa

Busch, C., Koch, T., Clasen, J., Winkler, E., \& Vowinkel, J. (2017). Evaluation of an organizational health intervention for low-skilled workers and immigrants. Human Relations, 70(8), 9941016. doi:10.1177/0018726716682308

Busch, C., Staar, H., Åborg, C., Roscher, S., \& Ducki, A. (2010). The neglected employees: Worklife balance and a stress management intervention program for low-qualified workers. In J. Houdmont \& S. Leka (Eds.), Contemporary occupational health psychology: Global perspectives on research and practice (Vol. 1, pp. 98-123). West Sussex, UK: John Wiley \& Sons Ltd.

Chen, B. W., Vansteenkiste, M., Beyers, W., Boone, L., Deci, E. L., Van der Kaap-Deeder, J., ... Verstuyf, J. (2015). Basic psychological need satisfaction, need frustration and need strength across four cultures. Motivation and Emotion, 39(2), 216-236. doi:10.1007/s11031-0149450-1

Cheon, S. H., Moon, I. S., \& Reeve, J. (2012). Experimentally based, longitudinally designed, teacher-focused intervention to help physical education teachers be more autonomy supportive toward their students. Journal of Sport and Exercise Psychology, 34(3), 365-396. doi:10.1123/jsep.34.3.365

Cheon, S. H., \& Reeve, J. (2015). A classroom-based intervention to help teachers decrease students’ amotivation. Contemporary Educational Psychology, 40, 99-111. doi:http://dx.doi.org/10.1016/j.cedpsych.2014.06.004

Cheon, S. H., Reeve, J., Yu, T. H., \& Jang, H. R. (2014). The teacher benefits from giving autonomy support during physical education instruction. Journal of Sport and Exercise Psychology, 36(4), 331-346. doi:10.1123/jsep.2013-0231 
Chiaburu, D. S., Van Dam, K., \& Hutchins, H. M. (2010). Social support in the workplace and training transfer: A longitudinal analysis. International Journal of Selection and Assessment, 18(2), 187-200. doi:10.1111/j.1468-2389.2010.00500.x

Chirkov, V. I. (2011). Human psychological autonomy: Reflections on the debates about its understanding in modern psychology. Social and Personality Psychology Compass, 5(9), 609-620. doi:10.1111/j.1751-9004.2011.00380.x

Colquitt, J. A., \& George, G. (2011). From the editors: Publishing in AMJ: Topic choice. The Academy of Management Journal, 54(3), 432-435. Retrieved from http://www.jstor.org.ezproxy.waikato.ac.nz/stable/23045090

Creswell, J. W., \& Plano Clark, V. L. (2017). Designing And Conducting Mixed Methods Research (3rd edition ed.). Thousand Oaks, CA: SAGE Publications, Inc.

Deci, E. L., Connell, J. P., \& Ryan, R. M. (1989). Self-determination in a work organization. Journal of Applied Psychology, 74(4), 580-590. doi:10.1037/0021-9010.74.4.580

Deci, E. L., Eghrari, H., Patrick, B. C., \& Leone, D. R. (1994). Facilitating internalization: The selfdetermination theory perspective. Journal of personality, 62(1), 119-142. doi:10.1111/j.1467-6494.1994.tb00797.x

Deci, E. L., \& Ryan, R. M. (1985). Intrinsic Motivation and Self-Determination in Human Behavior. NY: Plenum.

Deci, E. L., Ryan, R. M., Gagné, M., Leone, D. R., Usunov, J., \& Kornazheva, B. P. (2001). Need satisfaction, motivation, and well-being in the work organizations of a former eastern bloc country: A cross-cultural study of self-determination. Personality and Social Psychology Bulletin, 27(8), 930-942. doi:10.1177/0146167201278002

Deci, E. L., Schwartz, A. J., Sheinman, L., \& Ryan, R. M. (1981). An instrument to assess adults' orientations toward control versus autonomy with children: Reflections on intrinsic motivation and perceived competence. Journal of Educational Psychology, 73(5), 642-650. doi:10.1037/0022-0663.73.5.642

Deci, E. L., Speigel, N. H., \& Ryan, R. M. (1982). Effects of performance standards on teaching styles: Behavior of controlling teachers. Journal of Educational Psychology, 74(6), 852-859. doi:10.1037/0022-0663.74.6.852

Elo, A.-L., Ervasti, J., Kuosma, E., \& Mattila-Holappa, P. (2014). Effect of a leadership intervention on subordinate well-being. Journal of Management Development, 33(3), 182195. doi:10.1108/JMD-11-2012-0146

Greene, J. C., Caracelli, V. J., \& Graham, W. F. (1989). Toward a conceptual framework for mixedmethod evaluation designs. Educational Evaluation and Policy Analysis, 11(3), 255-274. doi:10.3102/01623737011003255

Grossman, R., \& Salas, E. (2011). The transfer of training: What really matters. International Journal of Training and Development, 15(2), 103-120. doi:10.1111/j.14682419.2011.00373.x

Güntert, S. (2015). The impact of work design, autonomy support, and strategy on employee outcomes: A differentiated perspective on self-determination at work. Motivation and Emotion, 39(1), 74-87. doi:10.1007/s11031-014-9412-7

Hardré, P. L., \& Reeve, J. (2009). Training corporate managers to adopt a more autonomysupportive motivating style toward employees: An intervention study. International Journal of Training and Development, 13(3), 165-184. doi:10.1111/j.1468-2419.2009.00325.x

Hitt, M. A., Beamish, P. W., Jackson, S. E., \& Mathieu, J. E. (2007). Building theoretical and empirical bridges across levels: Multilevel research in management. The Academy of Management Journal, 50(6), 1385-1399. doi:10.2307/20159480 
Hockey, G. R. J. (1997). Compensatory control in the regulation of human performance under stress and high workload: A cognitive-energetical framework. Biological Psychology, 45(1), 7393. doi:https://doi.org/10.1016/S0301-0511(96)05223-4

Holstein, J. A., \& Gubrium, J. F. (1995). The Active Interview. Thousand Oaks, CA: Sage Publications, Inc.

Ilardi, B. C., Leone, D., Kasser, T., \& Ryan, R. M. (1993). Employee and supervisor ratings of motivation: Main effects and discrepancies associated with job satisfaction and adjustment in a factory setting. Journal of Applied Social Psychology, 23(21), 1789-1805. doi:10.1111/j.1559-1816.1993.tb01066.x

Inceoglu, I., Thomas, G., Chu, C., Plans, D., \& Gerbasi, A. (2018). Leadership behavior and employee well-being: An integrated review and a future research agenda. The Leadership Quarterly, 29(1), 179-202. doi:10.1016/j.leaqua.2017.12.006

Jang, H., Reeve, J., \& Deci, E. L. (2010). Engaging students in learning activities: It is not autonomy support or structure but autonomy support and structure. Journal of Educational Psychology, 102(3), 588-600. doi:10.1037/a0019682

Joussemet, M., Mageau, G. A., \& Koestner, R. (2014). Promoting optimal parenting and children’s mental health: A preliminary evaluation of the how-to parenting program. Journal of Child and Family Studies, 23(6), 949-964. doi:10.1007/s10826-013-9751-0

Knowles, M. S., Holton, E. F., \& Swanson, R. A. (2012). The adult learner: The definitive classic in adult education and human resrouce development (7 ed.). New York, NY: Routledge.

Kühnel, J., Sonnentag, S., \& Bledow, R. (2012). Resources and time pressure as day-level antecedents of work engagement. Journal of Occupational and Organizational Psychology, 85(1), 181-198. doi:10.1111/j.2044-8325.2011.02022.x

Langan, E., Blake, C., Toner, J., \& Lonsdale, C. (2015). Testing the effects of a self-determination theory-based intervention with youth Gaelic football coaches on athlete motivation and burnout. The Sport Psychologist, 29(4), 293. doi:10.1123/tsp.2013-0107

Lewis, V., Martina, C. A., McDermott, M. P., Trief, P., Goodman, S. R., Morse, G. D., . . Ryan, R. M. (2016). A randomized controlled trial of mentoring interventions for underrepresented minorities. Academic Medicine, 91(7), 994-1001.

Lonsdale, C., Hall, A. M., Murray, A., Williams, G. C., McDonough, S. M., Ntoumanis, N., .. . Kolt, G. S. (2017). Communication skills training for practitioners to increase patient adherence to home-based rehabilitation for chronic low back pain: Results of a cluster randomized controlled trial. Archives of physical medicine and rehabilitation, 98(9), 17321743. e1737. doi:10.1016/j.apmr.2017.02.025

Mawritz, M. B., Mayer, D. M., Hoobler, J. M., Wayne, S. J., \& Marinova, S. V. (2012). A trickledown model of abusive supervision. Personnel Psychology, 65(2), 325-357. doi:10.1111/j.1744-6570.2012.01246.x

Ministry of Business Innovation \& Employment. (2018). Beyond Commodities: Manufacturing into the future. Retrieved from https://www.mbie.govt.nz/info-services/sectorsindustries/sectors-reports-series/pdf-image-library/manufacturing-report2018/manufacturing-sector-report-2018.pdf

Morgan, D. L. (1997). Focus Groups as Qualitative Research. Thousand Oaks, CA: Sage Publications, Inc.

Murray, A., Hall, A., Williams, G., McDonough, S., Ntoumanis, N., Taylor, I., .. . Lonsdale, C. (2015). Effect of a self-determination theory-based communication skills training program on physiotherapists' psychological support for their patients with chronic low back pain: A randomized controlled trial. Archives of physical medicine and rehabilitation, 96(5), 809816. doi:10.1016/j.apmr.2014.11.007 
Olesen, M. H. (2011). General causality orientations are distinct from but related to dispositional traits. Personality and Individual Differences, 51(4), 460-465. doi:10.1016/j.paid.2011.04.015

Oostlander, J., Güntert, S., \& Wehner, T. (2014). Linking autonomy-supportive leadership to volunteer satisfaction: A self-determination theory perspective. VOLUNTAS: International Journal of Voluntary and Nonprofit Organizations, 25(6), 1368-1387. doi:10.1007/s11266013-9395-0

Pelletier, L. G., Séguin-Lévesque, C., \& Legault, L. (2002). Pressure from above and pressure from below as determinants of teachers' motivation and teaching behaviors. Journal of Educational Psychology, 94(1), 186-196. doi:10.1037/0022-0663.94.1.186

Reeve, J. (2009). Why teachers adopt a controlling motivating style toward students and how they can become more autonomy supportive. Educational Psychologist, 44(3), 159-175. doi:10.1080/00461520903028990

Reeve, J., \& Cheon, S. H. (2014). An intervention-based program of research on teachers' motivating styles. In S. A. Karabenick \& T. C. Urdan (Eds.), Advances in Motivation and Achievement (Vol. 18, pp. 293-339). Bingley, United Kingdom: Emerald Group Publishing Limited.

Reeve, J., Jang, H., Carrell, D., Jeon, S., \& Barch, J. (2004). Enhancing students' engagement by increasing teachers' autonomy support. Motivation and Emotion, 28(2), 147-169. doi:10.1023/B:MOEM.0000032312.95499.6f

Rhoades, L., \& Eisenberger, R. (2002). Perceived organizational support: A review of the literature. Journal of Applied Psychology, 87(4), 698-714. doi:10.1037/0021-9010.87.4.698

Rigby, C. S., \& Ryan, R. M. (2018). Self-determination theory in human resource development: New directions and practical considerations. Advances in Developing Human Resources, 20(2), 133-147. doi:10.1177/1523422318756954

Ryan, R. M., \& Deci, E. L. (2017). Self-Determination Theory: Basic Psychological Needs in Motivation, Development, and Wellness. New York, NY: Guilford Publications.

Schultz, P. P., Ryan, R. M., Niemiec, C. P., Legate, N., \& Williams, G. C. (2015). Mindfulness, work climate, and psychological need satisfaction in employee well-being. Mindfulness, 6(5), 971-985. doi:10.1007/s12671-014-0338-7

Shanock, L. R., \& Eisenberger, R. (2006). When supervisors feel supported: Relationships with subordinates' perceived supervisor support, perceived organizational support, and performance. Journal of Applied Psychology, 91(3), 689-695. doi:10.1037/00219010.91.3.689

Slemp, G. R., Kern, M. L., Patrick, K. J., \& Ryan, R. M. (2018). Leader autonomy support in the workplace: A meta-analytic review. Motivation and Emotion, 42(5), 706-724. doi:10.1007/s11031-018-9698-y

Stenling, A., \& Tafvelin, S. (2016). Transfer of training after an organizational intervention in Swedish sports clubs: A self-determination theory perspective. Journal of Sport and Exercise Psychology, 38(5), 493-504. doi:10.1123/jsep.2016-0084

Su, Y.-L., \& Reeve, J. (2011). A meta-analysis of the effectiveness of intervention programs designed to support autonomy. Educational Psychology Review, 23(1), 159-188. doi:10.1007/s10648-010-9142-7

Taylor, F. W. (1911). The Principles of Scientific Management. New York, NY: Harper \& Brothers.

Twisk, J. (2006). Applied Multilevel Analysis: A Practical Guide for Medical Researchers. Cambridge: Cambridge University Press.

U.S. Department of Labor. (2018). Job Openings And Labor Turnover - July 2018. Retrieved from https://www.bls.gov/news.release/pdf/jolts.pdf. 
Vidyarthi, P. R., Erdogan, B., Anand, S., Liden, R. C., \& Chaudhry, A. (2014). One member, two leaders: Extending leader-member exchange theory to a dual leadership context. Journal of Applied Psychology, 99(3), 468-483. doi:10.1037/a0035466

Wellings, K., Branigan, P., \& Mitchell, K. (2000). Discomfort, discord and discontinuity as data: Using focus groups to research sensitive topics. Culture, Health \& Sexuality, 2(3), 255-267. doi:10.1080/136910500422241

Wheatley, D. (2017). Autonomy in paid work and employee subjective well-being. Work and Occupations, 44(3), 296-328. doi:10.1177/0730888417697232

Williams, G. C., \& Deci, E. L. (1996). Internalization of biopsychosocial values by medical students: A test of self-determination theory. Journal of Personality and Social Psychology, 70(4), 767-779. doi:10.1037/0022-3514.70.4.767

Williams, G. C., Grow, V. M., Freedman, Z. R., Ryan, R. M., \& Deci, E. L. (1996). Motivational predictors of weight loss and weight-loss maintenance. Journal of Personality and Social Psychology, 70(1), 115-126. doi:10.1037/0022-3514.70.1.115

Winkler, E., Busch, C., Clasen, J., \& Vowinkel, J. (2014). Leadership behavior as a healthpromoting resource for workers in low-skilled jobs and the moderating role of power distance orientation. Zeitschrift für Personalforschung, 28(1/2), 96-116.

Winkler, E., Busch, C., Clasen, J., \& Vowinkel, J. (2015). Changes in leadership behaviors predict changes in job satisfaction and well-being in low-skilled workers: A longitudinal investigation. Journal of Leadership \& Organizational Studies, 22(1), 72-87. doi:10.1177/1548051814527771

Yong, A., Roche, M., \& Sutton, A. (2019). Supervisory skills training for the neglected supervisors: development and preliminary evaluation of an autonomy-supportive programme. Industrial and Commercial Training. Advance online publication. doi:10.1108/ICT-01-2019-0013

Zeller, R. A. (1993). Focus group research on sensitive topics: Setting the agenda without setting the agenda. In D. L. Morgan (Ed.), Successful Focus Groups: Advancing the State of the Art. Thousand Oaks, CA: SAGE Publications, Inc. 